\title{
Consideraciones alternativas acerca de las rebeliones de esclavos en Santo Domingo
}

\author{
Roberto Cassá \\ Genaro Rodriguez Morel
}

Universidad Autónoma de Santo Domingo

En este trabajo los autores ponen de manifiesto algunas teorías relacionadas con las rebeliones de esclavos en el Santo Domingo colonial. Las mismas tienen como principal objetivo demostrar que estos levantamientos respondían a una concepción de carácter clasista, cuestión que ha sido rechazada por los principales representantes de la historiografia tradicional dominicana. Según los autores, las luchas que libraban los negros estaban justificadas por una consciencia social -individual o colectiva-producto de las contradicciones del sistema esclavista. Para sustentar esta teoría parten del concepto de acción social. Otro de los temas tratados en este artículo tiene que ver con la valoración que los autores hacen sobre la formación de una cultura alternativa por parte de los esclavos, en oposición a la cultura dominante. Hecho este que sirvió como catalizador de los conflictos sociales que se mantuvieron durante todo el periodo colonial.

\section{Las explicaciones de los historiadores}

En la tradición historiográfica de la República Dominicana se ha juzgado la rebelión de esclavos a la luz de parámetros sociales del período colonial que habrían estado normados por matrices culturales, de las cuales resultaba una naturaleza sui-generis, de validez absoluta. Partiendo de una constatación de sentido común transmitida por la memoria espontánea de los círculos dirigentes, se conformó la idea de que en todo momento los esclavos habrían aceptado el orden social.

En el fondo, el esclavo es un ausente de la relación histórica tradicionalista acerca de la colonia. En la medida en que se caracteriza a la cultura generada por la relación colonial como hispánica, el aporte demográfico y cultural africano es objeto de soslayo o 
de recusación abierta, dependiendo de los autores. ' En ese tenor, como se verá, aunque sujeta a matizaciones variables, una de las matrices decisivas de la historiografía ha sido la pretensión de identidad homogénea en el conjunto de la población. El esclavo no sólo carecía de peso numérico, de diferencia social palpable, sino que quedó anulado como agente específico por su actitud mimética generalizada.

Por otra parte, la presencia visible de población negra en el presente se atribuye a los procesos de "desnacionalización" del siglo XIX, provocados por la influencia de Haití. Esta apreciación se acompaña por juicios desembozadamente racistas, que imputan los orígenes de los problemas nacionales al factor africano. ${ }^{2}$ No obstante, se pregona la reiteración del patrón integrador de los dominicanos de piel negra, vistos en una dimensión esencial no africana. Esta interpretación ha sido erigida como uno de los fundamentos del tradicionalismo que postula la unidad nacional, fenómeno correspondiente a la ausencia de "prejuicios de castas" y hasta de división en clases sociales. ${ }^{3}$

En esas premisas se han sustentado las tesis que restan asidero al conflicto social por parte de los esclavos. Estas han variado desde la ausencia de referencias, la reducción al ámbito de lo delictivo o la afirmación de la incapacidad para una acción subjetivamente pautada.

Américo Lugo, a inicios del presente siglo, fue el primer investigador dominicano en visitar el Archivo General de Indias. Habiendo tenido evidencia documental, corrigió la imagen de la cuasi-inexistencia del negro, pero concluyó extendiendo a la segunda mitad del siglo XVI - a la que dedica el principal estudio que publicara- la tesis de la integración exhaustiva del esclavo a los parámetros de la cultura blanca.

1 Entre las muchas referencias se puede citar: "La raza etíope es por naturaleza indolente y no aplica su esfuerzo a ningún objeto útil..." Balaguer, Joaquín: La Realidad Dominicana. Buenos Aires, 1947, pág. 104.

2 "Antes del tratado de Basilea, en efecto, la población de la colonia estaba formada por la flor de las familias que habían emigrado a América con la sed del oro...". Ibídem, pág. 109.

3 Ibídem, pág. 119. 
No es casual su escasa atención a las informaciones de negros rebeldes, ni que eludiera el análisis de un hecho que se le revelaba masivo. Redujo la rebelión al ámbito de lo residual y se concentró a la justificación positivista de la integración socio-cultural, esgrimiendo el argumento de que la religiosidad hispánica operó como mecanismo atenuante de la esclavitud: "pero el sentido espiritual del alma española, o preponderaba sobre el interés o se confundía con éste". ${ }^{4}$

A tal efecto, Lugo separa radicalmente las condiciones de las colonias españolas de las vigentes en la vecina Saint Domingue, tipo de comparación que se ha afinado ulteriormente en la realizada con los establecimientos británicos. ${ }^{5}$ Con dicho recurso, explica un panorama global de integración de los esclavos, aunque no exento de respuesta álgida en el caso de maltrato:

"Eran, en general, dóciles, supersticiosos, fieles, agradecidos y vanidosos. El contacto social con el amo desarrollaba su facultad intelectiva... Preferían mil veces Santo Domingo a Africa... El genio e inclinación del negro se resentían del origen de éste; más en general dependían mucho del trato que recibían. Contento con la benignidad de sus amos, melancólico con su rigor, su tendencia a la arrogancia y la fiereza debía ser tenida siempre a raya." 6

Desde una óptica puramente hispanista, fray Cipriano de Utrera, erudito especialista en la historia colonial, puso énfasis en la integración del negro por medio de su aporte pasivo a la cultura criolla. De esta interacción, se deriva una constante de atemperamiento de los conflictos sociales:

"Esto mismo que en alguna manera es signo de atraso y de debilidad para producir un fruto típico de nacionalidad, fue como un sedante que suavizó toda aspereza y tirantez de clases que nunca pueden desaparecer... y por esa razón la historia dominicana de la era colonial está exenta de disturbios intestinos, de luchas, de aspiraciones... Todo era llano, democrático, sencillo..." 7

4 Lugo, Américo: Historia de Santo Domingo. Ciudad Trujillo, 1952, pág. 262.

5 Klein, Herbert S.: Slavery in the Americas. A comparative study of Virginia and Cuba. Chicago, 1967.

6 Lugo, Historia..., pág. 257.

7 Utrera, Fray Cipriano de: Historia militar de Santo Domingo. 3 vols. Ciudad Trujillo, 1951,1953. 
En investigaciones ulteriores a la confección de esa conferencia, Utrera pudo rastrear la acción de las bandas de cimarrones, pero no varió su perspectiva de asimilarlas a un fenómeno disfuncional, prácticamente delictivo. ${ }^{8}$ Según él, el escaso número de esclavos no habría permitido las condiciones para una conflagración social. Así, los alzamientos no pasaban de "...meras fugas a los montes... y las pandillas de huidos preferían mil veces huir más y más a lo recóndito de los montes, que atacar a sus perseguidores..." 9

Lugo estaba buscando un sustrato a la estructuración del conglomerado nacional, oponiendo lo hispánico a la incidencia norteamericana. Este reflejo de la intelectualidad nacionalista fue recuperado por el estado dominicano bajo la dictadura de Trujillo; pero el foco de oposición polarizadora varió: en adelante, lo hispánico quedó asociado a un concepto racial y a la subsecuente pugna sempiterna con la nación haitiana.

Los intelectuales, en una operación constructora de una cultura despótica, hicieron uso de argumentos carentes de fundamento empírico, no obstante la edición de fuentes que mostraban una tipología de esclavitud contrastante con la proclamada. ${ }^{10}$

En consecuencia, el más destacado de esos intelectuales, Manuel Arturo Peña Batlle, llegó a insinuar la inexistencia de un régimen de esclavitud en el período colonial, pues lo asimila a la comunidad dentro de España. ${ }^{11}$ Para este autor, hasta la entrada de los bucaneros, a mediados del siglo XVII, la isla constituía un homogéneo "tronco prístino" hispánico. ${ }^{12}$ Como es lógico, no se interesó por discutir el peso de la población negra, y lo que cuenta en el argumento es la asimilación exhaustiva de la población no blanca a los parámetros culturales hispánicos.

8 Utrera, Fray Cipriano de: La condición social de los negros en la época colonial. "Eme Eme", N. ${ }^{\circ}$ III, 17, marzo-abril, 1975, pág. 57.

9 Ibídem.

10 Entre otras colecciones de documentos, véase a Rodríguez Demorizi, Emilio: Relaciones históricas de Santo Domingo, 3 vols. Ciudad Trujillo, 1942,1957.

11 Peña Batlle, Manuel Arturo: El tratado de Basilea y la desnacionalización del Santo Domingo español, en Ensayos históricos. Santo Domingo, 1989, págs. 47-84.

12 Peña Batlle, Manuel Arturo: El sentido de una política, en Política de Trujillo. Ciudad Trujillo, 1954, pág. 66. 
Carlos Esteban Deive, el autor que más recientemente ha estudiado los alzamientos de esclavos, admite un tipo de conexión -que finalmente no aclara- entre el movimiento social y la estructura esclavista. No obstante, mantiene los matices tradicionalistas de Utrera cuando, polemizando con historiadores haitianos, niega sentido de identidad y contenido proyectual clasista y colectivo a la acción de los cimarrones alzados en los bosques:

"La subordinación económica, jurídico-política y socio-cultural en que se hallan inmersos los esclavos no les permite ninguna posibilidad de llegar, como clase social, a un entendimiento elaborado y crítico de su situación. El estado de dependencia, así como los valores y pautas de comportamiento impuestos por la clase dominante y creados y recreados a lo largo de un proceso sutil pero consciente de deculturación y socialización, les impiden alcanzar una inteligencia política de su enajenación y de su lucha revolucionaria...esas acciones no son el resultado de una comprensión lúcida y auténtica de su condición servil ni una expresión cabal de las contradicciones de clase propias del sistema esclavista... los esclavos nunca lograron plantear sus reivindicaciones como miembros de una clase social en pugna con la dominante, sino que se redujeron a obtener la libertad como individuos y no como protagonistas de los antagonismos de clase..."13

\section{Contexto histórico y esbozo del problema}

En el presente escrito, en oposición a la tesis de Deive, se propone la identificación de la actitud de la población esclava a través del movimiento social y, específicamente, de las diversas tipologías de sublevaciones. Por ello, queda delimitado a discutir la posición de los esclavos en el lapso en que muchos de ellos se hallaban en estado de sublevación; esto comenzó concomitantemente con el inicio de la trata, alrededor de la segunda década del siglo XVI, y se prolongó hasta 1667.

La causa principal de las rebeliones estribaba en el régimen social existente, caracterizado por un sistema de esclavitud intensiva

13 Deive, Carlos Esteban: Los Guerrilleros Negros. Santo Domingo, 1989, pág. 16. 
vinculado a la exportación de géneros agrícolas. No obstante, no se examinarán las características de este sistema, las cuales ya han sido objeto de atención. ${ }^{14}$ Cabe señalar, empero, que la estructuración de un esbozo de sociedad de plantación comportó fragilidades básicas a consecuencia de las condiciones desfavorables que interponía el estado español a los intereses de los hacendados. Por tal razón, si bien se conformaron relaciones similares a las de las colonias de plantación de Inglaterra y Francia, distaron del grado de la exhaustividad de éstas.

Entre otros componentes de esta situación específica se encuentra el rápido agotamiento de las bases de la esclavitud intensiva. El aspecto principal que operó al respecto fue la insuficiencia de la demanda en el mercado español, agudizada por las prácticas monopólicas que impedían los intercambios con mercaderes de otros países.

La crisis de la economía azucarera fue uno de los factores que incidió en los cambios experimentados dentro del modelo esclavista, haciendo de este un sistema cada vez menos rígido. A esto se vino a sumar la quiebra del comercio regular con la metrópoli.

Así, los hacendados de Santo Domingo no lograron acceso al mercado mundial, salvo en momentos tardíos por medio del contrabando. La formación de los capitales de los pobladores blancos establecidos en la isla se había producido durante la etapa de la minería del oro, el cual se extraía mediante la explotación de los aborígenes nativos.

Estos capitales se pudieron destinar al sistema de plantaciones gracias a concesiones otorgadas por la Corona como medio de evitar la despoblación de la isla cuando desaparecieron casi todos los indios; posteriormente, los ritmos de acumulación más bien entraron en fase de desgaste, aunque se alternaran fases de prosperidad con otras más prolongadas de dificultades.

El grueso de hacendados, a merced de los mercaderes sevillanos, se debatía en un equilibrio catastrófico, responsable de no pocas quiebras o trasiegos de propiedades. De tal manera, llegó el momen-

14 Cassá, Roberto: Historia social y económica de la República Dominicana. 2 vols. Santo Domingo, 1976-1980, vol. I, págs. 65-92. 
to en que la tipología de la plantación comenzó a ser sustituida por nuevas relaciones, hasta quedar por completo anulada. Puesto que en este trabajo se postula la articulación entre sistema y práctica social, en torno a esta evolución de la estructura económico-social es como se establece el criterio de periodización.

Se ha sugerido que la despoblación de las zonas occidentales de la isla, como recurso para erradicar el comercio ilegal, en 1605 y 1606, marcó el hito decisivo en el giro de todo el proceso histórico. ${ }^{15}$ En realidad, si bien las devastaciones conmovieron la vida insular, sus efectos se restringieron, en lo inmediato, a acentuar tendencias que venían presentándose desde al menos dos décadas antes. Por todo ello, se propone la siguiente periodización de los componentes del régimen social:

1520-1580: Expansión de la plantación esclavista

1580-1605: Inicio de la decadencia de la plantación

1605-1645: Profundización de la decadencia

1645-1665: Transición a un nuevo patrón de economía y esclavitud

Así pues, la plasmación final de las tendencias de descomposición del sistema sólo tuvo lugar en la segunda mitad del siglo XVII. Y, si bien es cierto que para el período ulterior las descripciones de los historiadores dan cuenta de aspectos de la realidad, éstas no son válidas para el conjunto del período considerado. A medida que decaía la viabilidad de la esclavitud intensiva, se generaban alternativas funcionales, pero éstas no borraban los patrones sociales e institucionales que daban por resultado la actitud conflictiva de la masa esclava respecto al orden. En consecuencia, aunque se produjo, en términos generales, un condicionamiento de las relaciones sociales sobre la acción de los sujetos, esa correspondencia fue sólo parcial: como muestran las persistentes actitudes insurreccionales de los esclavos, buena parte de éstos prefirió igno-

15 Mir, Pedro: La noción de periodo en la historia dominicana. Santo Domingo, 1981, pág. 20 ss. 
rar las opciones de mejoría social que ofrecía el debilitamiento sistemático de la plantación.

Un problema asociado consiste en los efectos de la debilidad del sistema esclavista; sin duda facilitaron un proceso temprano de gestación de rasgos culturales criollos y aun situaciones irregulares - de acuerdo a los patrones institucionales - de una parte de la masa esclava. No obstante, la reproducción de las líneas dominantes del sistema conllevaba la persistente actitud refractaria de la masa subordinada.

En síntesis, pues, debe ser rechazada la generalización extrapolada por los historiadores acerca del carácter benigno de la esclavitud y, no menos, de la subsiguiente ausencia de resistencia social y de reivindicación de identidad cultural entre los esclavos. Adicionalmente, aun si se reconoce una dinámica por completo distinta a partir de la segunda mitad del siglo XVII, ello no conlleva la aceptación de las tesis tradicionalistas sobre la ausencia de lucha social y de diversidad de identidades, punto éste que apenas será esbozado ya que escapa a los propósitos aquí delineados.

En contraste con las aseveraciones del cuasi-invariante tratamiento patriarcal, las características del esquema de plantación condenaban a los esclavos de Santo Domingo a condiciones de vida en extremo crueles. La esclavitud intensiva se condensaba alrededor de la producción azucarera, pero se reproducía en sus trazos esenciales en los restantes rubros agrícolas. Un documento, entre no pocos, ilustra el mortífero régimen de labores:

"... los hazen trabajar diez y ocho oras del día natural sin apartarse un punto del trabajo ni aun para comer, porque eso poco que les dan lo comen en pie trabajando y quando los sueltan se caen en el suelo hecho pedazos de sueño y trabajo, y el día de fiesta, que no guardan, sino hasta bispera, unos le duermen, otros que son mas diligentes siembran yuca para hazer casabe porque no les dan otra cosa para comer, sino carne de baca y aun tasadamente y poco menos todos andan las carnes de fuera, de cuya causa les mueren muchos." 16

16 Archivo General de Indias (en adelante AGI), Santo Domingo, 51. Fray Diego de Santa María al rey. Santo Domingo, 30 de abril de 1573. 
En otro documento se establece la conexión entre el régimen de vida y la propensión a la rebelión:

"En los yngenios, estancias y hatos no dan de comer a los negros ni de vestir y les hazen trabajar domingos y fiestas y noches y días sin darles doctrina y lo mismo se haze con los indios y destos demasiados trabajos y malos tratamientos e de no darles comida los negros se alzan, y se hazen cimarrones..." 17

El funcionamiento del sistema generó una estructura demográfica caracterizada por la primacía del aporte africano. Mientras el número de vecinos blancos o mezclados oscilaba entre 1.000 y 1.200 familias, como secuela de las emigraciones sucesivas hacia el continente, los esclavos pudieron haber llegado por momentos a las 30.000 personas. ${ }^{18}$ Del cotejo de las diversas estimaciones se puede inferir que, normalmente, en la etapa de auge de la plantación azucarera, oscilaban entre 20.000 y 25.000 negros.

Una parte considerable de esa población se hallaba en los ingenios azucareros, cuyo número fluctuó en la fase de auge entre 30 y 40 unidades productivas, incluyendo los trapiches. ${ }^{19}$

La dotación de los ingenios oscilaba, salvo casos aislados, sobre unos 80 en los primeros años de iniciada la economía azucarera. Posteriormente los mismos llegaron a tener hasta 350 esclavos. $^{20}$

17 Ibídem. Memorial del Dr. Cuenca al rey. Santo Domingo, 24 de abril de 1579.

18 Un contemporáneo señala: "Creo yo que pasan de 25. o de 30. mil Negros los que hai en esta isla, i no hai en toda ella 1200 Vecinos." Alonso de Castro, arcediano de la catedral, al Consejo de Indias, Santo Domingo, 26 de marzo de 1542, en Marte, Roberto: Santo Domingo en los manuscritos de Juan Bautista Muñoz, Santo Domingo, 1981, pág. 396. AGI, Santo Domingo, 71. La cifra mínima encontrada en los documentos es de 12.000. Andrés de Carvajal, arzobispo de Santo Domingo, al rey. Santo Domingo, 28 de agosto de 1569. No obstante, en un momento en que había comenzado la disminución de la población esclava se siguió estimando en más de 25.000. Clemente Grajeda, alcaide de la fortaleza, al rey, Santo Domingo, 25 de mayo de 1582. AGI, Santo Domingo, 51.

19 Una relación accesible de los ingenios en Fernández de Oviedo, Gonzalo: Historia general y natural de las Indias, 5 vols. Madrid, 1959, págs. 106-110. Otra lista en AGI, Justicia, 12, reproducida en Sobre Catedral de Santo Domingo e Iglesias de los Ingenios 1533-1535, "Casas Reales”, N. ${ }^{0}$ 19. Santo Domingo, octubre 1988, págs. 89-141.

20 Rodríguez Morel, Genaro: Esclavitud y vida rural en los ingenios azucareros de Santo Domingo. S.XVI. "Anuario de Estudios Americanos”, tomo XLIX, Sevilla, 1992, páginas 89-117. 
Hacia finales de la segunda mitad del siglo XVI, gran parte de los esclavos ya no se encontraba en ingenios, sino que laboraba en estancias y unidades similares, donde el régimen de esclavitud, aunque menos duro que en los ingenios, no se diferenciaba sustancialmente. El inicio de la decadencia de la economía de plantación determinó una variación de la proporción de esclavos en los diversos tipos de unidades productivas. El incremento de las exportaciones de jengibre - rubro típico de las estancias de la época- y el atractivo del comercio ilegal fueron todos factores que redujeron el influjo del sector azucarero.

Para sostener ese sistema social, basado en una aguda polaridad, se tuvo que hacer uso de un régimen de excepción. Desde que se evidenciaron las necesidades de orden, las autoridades coloniales promulgaron reglamentos que establecían rigurosos cánones de disciplina y castigos. En las ordenanzas de 1528, por ejemplo, se prohibían los desplazamientos de esclavos desde una hacienda a otra, sin importar el motivo, aunque aludiéndose a las fiestas como ocasiones de gestación de intentos sediciosos; entre muchas disposiciones, se ordenaba a todos los hacendados que mantuvieran cepos y otros instrumentos de castigo. ${ }^{21}$ Los reglamentos estaban concebidos desde el ángulo de reprimir la protesta y preservar el sistema de trabajo. Aunque su validez se prolongó hasta el siglo XVIII, más tarde fueron objeto de ajustes, al comprobarse que la severidad excesiva estimulaba la rebelión. ${ }^{22}$

Dentro de este contorno estructural, las posibilidades de mejoría eran casi nulas, incluyendo las de manumisión. Cierto que esta opción no estaba del todo cerrada, pero no porque el sistema estuviese normado por una actitud patriarcal de los amos, sino por las grietas que afrontaba crónicamente. De tal suerte, éstas tendían a manifestarse en variantes como el uso excesivo de domésticos, la actividad de los jornaleros y las negras denominadas "ganadoras".

21 Están reproducidos en Utrera: Historia militar, tomo I, págs. 202-209.

22 En cuanto a las fugas de los esclavos el licenciado Cerrato afirmaba que de cien negros que se iban al monte, noventa y nueve lo hacían por los malos tratos que recibían y por las crueldades de sus dueños y los que los mandan. AGI, Santo Domingo, 77, ramo V, doc. 134. Cerrato a S.M. Santo Domingo, 12 de septiembre de 1544. 
Aunque no se dispone de información estadística que relacione cuantitativamente esclavos y libertos, el cotejo de fuentes permite descartar las conclusiones de que las manumisiones se generalizaron desde el siglo XVI.

Además del pésimo trato, los esclavos de las plantaciones carecían prácticamente de instrucción religiosa. Esto se debía a la falta de consideraciones efectivas que atenuaran el sistema de trabajo y a que los recursos de la iglesia por concepto de diezmos se concentraban en el fausto del Cabildo eclesiástico, quedando descuidados los curatos de zonas de ingenios y estancias. Además de la segmentación social, operaba, pues, una no menos tajante en la cultura. Los hacendados, agrupados en el Cabildo de Santo Domingo, se opusieron a la apropiación de diezmos por el arzobispo, ${ }^{23}$ pero el verdadero objeto de la disputa radicaba en el control de los diezmos por concepto de los azúcares, de los cuales los sectores azucareros tenían que dar al Cabildo eclesiástico una arroba por cada 30 de azúcar blanco que produjeran, lo mismo correspondía al pago del diezmo.

De ahí que, combinadas las segmentaciones sociales y culturales, la masa esclava desarrollara un sentido inequívoco de identidad. Es cierto que estaba atravesado por particularismos y que avanzaba un proceso de criollización por medio del cual quedaban incorporadas pautas culturales de los blancos. Ahora bien, no se puede postular - al estilo de Lugo y Utrera - una relación excluyente entre criollización e identidad diferenciada, por cuanto no puede encontrarse en el siglo XVI una cultura criolla homogénea, sino tendencias a su conformación por medio de subculturas expresivas de acciones sociales agudamente contrapuestas. Las condiciones de vida de los esclavos tendieron a dotarlos de parámetros culturales comunes - por encima de particularismos étnicos-, expresamente diferenciados de los blancos.

La criollización estuvo obstaculizada, justamente, por el hecho de que a lo largo de todo el siglo XVI, en su mayoría los esclavos eran bozales, es decir nacidos en Africa. El avance de la proporción

23 Diezmos de azúcar 1551-1574, "Casas Reales", N. ${ }^{\circ}$ I, 19 de octubre de 1988, págs. 145-348. Se reproduce lo esencial de AGI, Justicia, 983. 
de ladinos - nacidos en la isla o en otros territorios cristianos- fue lento a consecuencia de la alta mortalidad que deparaba el ritmo de trabajo y de las desiguales proporciones entre los sexos. Es hacia mediados del siglo XVII cuando se puede estimar que comenzaron a primar los ladinos o criollos; esto no era posible en el siglo XVI, cuando por períodos entraban anualmente contingentes de hasta 2,000 bozales. ${ }^{24}$ Se daba una asociación entre modalidad intensiva de esclavitud y un patrón demográfico; la alteración de este último, en beneficio de los nacidos in situ, fue expresión elocuente del final del esquema de plantación.

Ahora bien, mientras la mayoría estuvo compuesta por bozales, y una buena parte de ellos de ingreso bastante reciente, se entorpecía la formación de una cultura única de esclavos, a causa de la diversidad étnica africana. Esta composición daba lugar a pugnas frecuentes entre agregados étnicos; ahora bien, al mismo tiempo, hacía obligada la adopción de patrones culturales compartidos, que iban sedimentando localmente.

Los propios hacendados, deliberadamente, promovieron la mezcla de miembros de etnias muy diversas, con propósito antiinsurgente, como se muestra en los inventarios de ingenios y en otras listas de esclavos. ${ }^{25}$ No obstante, el resultado fue la conjugación entre la inevitable criollización -empezando por el uso del idioma castellano- y la persistencia de componentes intactos del legado cultural africano, potenciados por etapas de predominio de la entrada de ciertas etnias; fue particularmente masiva la presencia de angolanos desde fines del siglo XVI.

Paradójicamente, la división entre etnias no dejó de comportar la gestación de una forma de solidaridad, sólo que referida a la etnia. En este sentido se dificultaba la emergencia de una cultura unificada y de un sentido común de identidad.

24 AGI, Santo Domingo, 49. El licenciado Estévez, fiscal de la real Audiencia, al rey, Santo Domingo, 10 de diciembre de 1552.

25 Es accesible el inventario del ingenio de Hernando Gorjón, donado para la creación de un colegio, que a la pọstre sería la universidad de los jesuitas. Véase Incháustegui, Joaquín Marino: Reales Cédulas y correspondencia de gobernadores de Santo Domingo, 5 vols. Madrid, 1958, tomo I, págs. 236-243. 


\section{Sentido clasista de las rebeliones}

La total marginación socio-cultural a que quedaban condenados los esclavos por los cánones del sistema tornaba lógica la prolongación africana. A partir de tal complejidad socio-cultural se explica que hubiese un caldo de cultivo crónico para la rebelión, condensación expresiva del rechazo generalizado del orden, y, por ende, mecanismo de acción de clase.

La rebelión era el correlato de la aspiración generalizada a la vida libre. De ahí que propendiera al designio de la reconstrucción del patrón de vida de la tribu africana. No se trataba de una aspiración aleatoria, sino ratificada por la lógica sistémica, en la medida en que ésta no permitía el acceso a la libertad por otros medios. El expediente venía a ser, entonces, la forma de concreción más intensa de un sentir generalizado de clase. El hecho de que la mayoría de los esclavos no se alzase no descarta el sentido clasista de la rebelión, puesto que rebeldes y pacíficos compartían el mismo fin y éste sólo se lograba manifiestamente con la fuga.

La posición de Deive, consistente en recusar el contenido clasista de la acción de los cimarrones, presenta, desde este ángulo, inconsistencias fundamentales. Para esclarecer el problema habría que partir de una conceptualización de la acción de clase. Esta puede definirse como la que se réfiere a términos de reproducción de las relaciones de producción; esto implica la gestación de un sentido subjetivo compartido, expresado en matrices culturales. ${ }^{26}$ En rigor, no hay clase sin acción clasista, y toda clase tiene una conciencia correspondiente no sólo a su interés, sino a condicionamientos históricos particulares. Las confusiones que se han originado sobre este problema provienen de la imputación de una conciencia ideal de clase, que no resulta sino de una operación ideológica y política; por esto se ha concluido a veces en que la clase sólo es una categoría válida para la sociedad capitalista. ${ }^{27}$ na, 1977.

26 Thompson, E.P.: La Formación Histórica de la Clase Obrera., 2 vols. Barcelo-

27 Lukács, Georg: Historia y conciencia de clase. Barcelona, 1975. 
La organicidad clasista de la rebelión puede afirmarse desde tres ángulos: su persistencia, la inclusión de amplios contingentes y el apoyo de que gozó entre la generalidad de la población esclava. La narración que se expone más abajo dará cuenta, precisamente, de la virtualidad de estas tres condiciones. Ahora bien, la organicidad clasista no excluía la segmentación de identidades y la fractura de los intereses operantes entre grupos cuyo mecanismo de conformación podía variar: relaciones étnicas, comunidad en un centro de trabajo, oficio o ubicación en las relaciones sociales, parentesco, la solidaridad resultante de la cooperación en el alzamiento, etc. No obstante, el hecho de que no quedara aclarada una perspectiva inclusiva de todo el conglomerado no autoriza la afirmación de que la rebelión obedecía a una motivación individual, lo que la eximiría de carácter colectivo y, por ende, clasista. ${ }^{28}$ Por otra parte, aun cuando la solidaridad de la mayoría con el acto insurrecto era inequívoca, no implicaba la interiorización del móvil en toda la masa; sin que se redujese la insurrección a un plano de idealidad abstracta, lo que le confiere connotación clasista es que, en los hechos, exteriorizaba, en su forma más global, la oposición amos-esclavos.

Cuando Deive asegura que la rebelión de esclavos estaba descontextualizada de un condicionamiento clasista incurre en la inconsistencia de utilizar una categoría de análisis histórico que no le sirve para explicar el proceso que estudia. Reproduce la visión de limitar la clase al ámbito de la relación estructural, y concluye despojando de la condición de sujetos a los esclavos. Lo que les demanda, acerca de la lucidez del proyecto o comprensión de su situación, muestra un típico anacronismo resultante de un tratamiento de la fuente restringido a la lectura al pie de la letra, lo que conlleva a la incomprensión de los móviles que animan la acción de los grupos.

La definición de tales móviles no puede llevarse a cabo mediante un procedimiento hermenéutico tradicional, ya que los esclavos no emitían documentos, muy pocas veces se les incluía en los interrogatorios de organismos oficiales, y cuando se hacía era para

28 Deive, Los Guerrilleros..., pág. 16. 
reafirmar supuestos de las partes interesadas. La clave de esta atribución de sentido se debe hallar en la interpretación de la acción, en base al registro empírico de las fuentes, aunque no atenida al mismo. Es, pues, la conexión teórica entre sistema y práctica social registrada la que permite desentrañar la pertinencia y el sentido de tal práctica. Aun así, el cotejo de fuentes autoriza la conclusión del carácter colectivo de la acción insurreccional, las premisas de su contenido clasista y la lógica que conllevaba en el designio de construcción de un esquema ideal compartido de vida libre.

\section{Tipología de las rebeliones}

La manera en que se produce la acción ofrece pistas acerca de los móviles de sus participantes; al mismo tiempo, su frecuencia permite caracterizar períodos. Desde esa óptica, se puede establecer una clasificación partiendo de las acciones de menores alcances.

La forma más elemental es la huida individual, en el entorno de la unidad productiva. Este tipo de acto puede haber sido pautado por una búsqueda pasajera de alivio o de diversión, o haber quedado restringido por la falta de criterios para una actividad de mayor envergadura. Esto último explica que al principio esta forma de rebeldía fuera la más extendida, y que luego decayese, conscientes quienes la ejercían de que estaban expuestos a ser capturados con facilidad y a ser sometidos a castigos.

Una modalidad más desarrollada fue la de reducidos grupos que se cohesionaban en torno a un propósito definido de fuga y se internaban a zonas muy remotas. De igual manera que en la anterior tipología, ésta se encuentra muy frecuentemente en etapas iniciales, aunque con cierta tardanza después del establecimiento de la trata. La misma es una forma de cimarronaje, es decir, de voluntad deliberada de organizar una vida libre, al margen de la ley de los amos.

En la medida en que la acción anticimarrona se hizo sistemática, se dificultaba la pervivencia de los pequeños grupos propios del anterior tipo. Poco a poco se fueron conformando, entonces, am- 
plios contingentes que dieron lugar a palenques. Estos eran establecimientos aldeanos, regidos por un sistema defensivo

El carácter más desarrollado es el que se puede denominar cimarronada: se trata de una campaña continua de depredaciones contra la vida y las propiedades de los blancos. Las cimarronadas tuvieron vigencia durante toda la década de los años 40 por razones que se verán más abajo.

A veces, las cimarronadas se vinculaban a rebeliones de una porción considerable de la población de un ingenio. Salvo en uno de los casos conocidos, este acto lo que hacía era engrosar una banda cimarrona preexistente. Por esto cabe también distinguir entre la rebelión de una unidad productiva y la cimarronada. Ahora bien, la experiencia dictaminó que esta tipología de rebelión careciese de perspectiva si no se engrosaba o daba lugar a una cimarronada.

Tanto la cimarronada como la rebelión de unidad tenían por designio la liquidación de la presencia blanca, es decir, el dominio indisputable del territorio. En cambio, los palenques y los otros tipos asumían una faceta defensiva, procurando la libertad en coexistencia con el dominio colonial. Como resultado de esto, el palenque se convertía en una unidad cultural, donde convergían los diferentes modos de vida del conglomerado negro.

\section{Las primeras manifestaciones}

Desde el momento en que la trata adquirió amplias dimensiones y los esclavos se familiarizaron con el nuevo escenario histórico, la rebelión adquirió vigencia y constituyó un flanco débil para la estabilidad del orden.

Como debían conjugarse ambas condiciones, los primeros rebeldes que tuvieron éxito en sostenerse de manera prolongada fueron aquellos que se unieron a las bandas de indios cimarrones que comenzaron a operar desde antes de 1520, y de las cuales la más importante fue la comandada por el cacique Enriquillo. Los indígenas no sólo trasmitieron a los negros su consustanciación con el medio, sino que les enseñaron la táctica con la cual podían sobrevivir 
en libertad, la que de ninguna manera se basaba en enfrentamientos masivos y frontales.

Ahora bien, la propensión insurreccional de los negros no fue originada entre los indígenas. Desde que llegaron los primeros grupos de ladinos, durante la gobernación de Nicolás de Ovando (15021509), las autoridades captaron el peligro que esto representaba e informaron de su proclividad conflictiva. Por temor a que siguieran rebelándose, se ordenó disminuir la importación de africanos. No parece, empero, que lograran sostenerse en libertad durante períodos prolongados, puesto que debían carecer de una concepción de cómo eludir la persecución.

La falta de tal instrumento conceptual adecuado es lo que explica la famosa rebelión de 1521 acaecida en el ingenio de Diego Colón, entonces virrey, en las navidades de 1522. La misma estuvo encabezada mayoritariamente por negros jelofes. Seguramente, el alzamiento fue facilitado por la comunidad étnica de sus protagonistas, quienes no debían tener un plan muy definido, a no ser el exterminio de todo blanco. El propósito que se puede discernir es que pretendían incorporar al mayor número posible de esclavos, indicador del móvil mencionado. Por ello, marcharon hacia el ingenio del licenciado Zuazo, otro miembro de la élite administrativa, lo que dio la oportunidad para que fuesen aniquilados. ${ }^{29}$

Que sepamos, los jelofes no tuvieron ninguna relación con los indios, y esto es un componente sintomático acerca de la modalidad que asumieron de delinear una ofensiva frontal. La lección que deparó el levantamiento debió ser bien procesada, porque algo similar sólo vino a repetirse más de 20 años después. Pero la misma asimilación a las bandas de indios rebeldes requería de una experiencia, por lo cual en la tropa de Enriquillo fue minúscula la presencia de africanos.

29 AGI, Patronato 22, doc. 2, ramo 2. Carta Real en respuesta a la comunicación enviada por la Audiencia. Pamplona, 27 de diciembre de 1523. Debemos destacar que el alzamiento de los negros jelofes no fue un hecho aislado. Decimos esto, porque el año siguiente de 1523 se repitieron los mismos levantamientos en otras partes de la isla. A esto se refieren los miembros de la Audiencia de Santo Domingo diciendo que, además de los ne:gros levantados en el ingenio del Almirante, también andan otras cuadrillas. 
Adicionalmente, debe tomarse en consideración que en la cotidianidad se abrieron conflictos -estimulados por los blancosentre negros e indios. Estos se agudizaron cuando Enriquillo claudicó y se comprometió, a cambio de la garantía de libertad a todos sus acompañantes, a perseguir a todo aquél que se rebelase, no importando que fuese negro o indio. ${ }^{30}$ Algunos acompañantes de este cacique y, en tiempo posterior, del cacique García serían los más eficientes guías de las cuadrillas anticimarronas. En represalia, Francisco Lemba, uno de los más prominentes caudillos cimarrones, hizo incendiar una de las aldeas de antiguos acompañantes de Enriquillo - a orillas del lago que hoy lleva su nombre-, y asesinar a gran parte de sus habitantes.

A pesar de este motivo de conflicto, todavía después de 1533 , fecha de rendición de Enriquillo, siguió produciéndose la colaboración entre indios y negros rebeldes. Se debe tener en cuenta que la concesión de libertad otorgada por Carlos $\mathrm{V}$ únicamente cubría a los acompañantes del cacique. Como los indios seguían teniendo mayor dominio del terreno, persistió el expediente de que fuesen los negros los que se agregasen a las formaciones rebeldes de los primeros. Aparte de pequeños grupos de indios fugitivos, se sabe que al menos el cacique Murcia se rebeló, refugiándose finalmente en la península de Samaná, hasta donde fue perseguido por súbditos del cacique García, recién liberados de la encomienda que gozara Juan de Villoria. De igual manera, se sabe que restos de la primera cimarronada se recompusieron en una banda de indios rebeldes.

La promulgación de las Leyes Nuevas por Carlos V, en 1542, las cuales otorgaban la libertad a los indios, restó beligerancia a éstos, aunque, por el contrario, incentivó al levantamiento de negros. Actuó también en el desplazamiento la rápida reducción del número de indios, ya en menos de 100 los naturales de la isla al final de la década de 1540.

30 Utrera, Fray Cipriano: Polémica de Enriquillo, Santo Domingo, 1973, passim. 


\section{Persistencia de rebeliones y palenques}

Aunque el designio principal de los apalencados consistía en la garantía de la libertad, no podían prescindir de cierta actitud ofensiva. De vez en cuando, bajaban a las zonas llanas y atacaban establecimientos de blancos, con el doble móvil de debilitarlos y de procurarse bienes para su subsistencia. Así, en la medida en que la administración colonial debilitaba su presencia en el campo, se acrecentaba la disposición beligerante de los apalencados. Cada cierto tiempo resultaba necesaria la realización de batidas que retornasen a los negros a la defensiva. Es lo que ocurrió en los años ochenta, en medio del auge del contrabando con enemigos de España por parte de los hateros y hacendados de La Yaguana, la población más cercana del Bahoruco. Como los blancos actuaban al margen de la ley, se facilitaba a los rebeldes atacar sus establecimientos. La Audiencia promovió entonces una ofensiva. ${ }^{31}$ No obstante seguía la disposición ofensiva, manifestada en reiterados ataques:

"muchos hay y han ido en tanto aumento que han hecho una pobla-
cion y poblaciones que llaman el Baoruco, adonde tenemos noticia
que hay cantidad de gente, y cada día vienen a los ingenios y roban
negros; a unos llevan por fuerza y a otros de voluntad, y aun se
comunican con algunos negros mansos de secreto, y así se van en-
cimando y fortificando, y tienen tanto atrevimiento y desenvoltura
que ya nos vienen a echar de nuestras casas sin que los podamos
resistir..." 32

Tanto el número de alzados como las acciones que iban a realizar concitaron la preocupación de las autoridades. El volumen de noticias acerca de estos palenques da cuenta de lo que representaron en la época. Por ejemplo, el presidente de la Audiencia estimó como altamente perjudiciales los daños que recibían las finanzas reales de parte de los alzados del Bahoruco, quienes, según él, podrían llegar a quinientos y se encontraban en tal estado desde

31 Utrera, Historia Militar.., Tomo II, pág. 83 y ss.

32 El Cabildo de La Yaguana al rey, 5 de marzo de 1587, Ibídem, pág. 86. 
cincuenta años atrás. ${ }^{33} \mathrm{~A}$ pesar de su declarada impotencia, parece que la Audiencia se dedicó a recopilar información detallada acerca del modus operandi de los cimarrones; por lo menos, entre otros detalles, se llegó a la conclusión de que en el Bahoruco existían cuatro poblaciones asociadas. ${ }^{34}$ Para el funcionario, el problema carecía de solución por la escasa población blanca y los subidos gastos que conllevaría intentar la reducción: estimó que al menos se requeriría una tropa de cien hombres. ${ }^{35}$ Uno de los actos más llamativos de estos cimarrones fue el incendio de San Juan de la Maguana, ${ }^{36}$ villa que poco después de hecho fue evacuada, al grado que se certificó el sitio como exclusivamente poblado por grifos ${ }^{37}$ dispersos. En varias ocasiones las milicias de La Yaguana intentaron controlar las acciones de los cimarrones, pero más bien incitaron un incremento de su beligerancia. Se apoderó de los vecinos un estado de pánico por la posible pérdida de toda la isla.

Aunque durante un período la concentración del Bahoruco fue la que más llamó la atención, no fue la única. Ya se ha visto el caso de un palenque oculto muchos años en las sierras de Higuey. En fecha indeterminada, pero que puede situarse hacia 1537 por un documento similar fechado, el Cabildo de Santo Domingo da cuenta de un estado continuo de depredaciones en los alrededores de la ciudad, lo que incluyó una incursión en las riberas del Haina:

"los negros... que se alzan a los montes y bajan y asaltan las ciudades y pueblos y aldeas: estos no andan a pie sino a caballos. Estos, además de asaltar llegaron por el río Haina y se llevaron de allí 20 esclavos." ${ }^{38}$

33 AGI, Santo Domingo, 72. Memorial de Lope de Vega Portocarrero a S.M., 4 de julio de 1589. En otro de los documentos emitidos a propósito del tema, el funcionario dató la presencia a cuarenta años. Si se considera desde el ángulo de una ocupación estable y continua, este estimado da cuenta mejor de la realidad, ya que coincide con el final de las tres mayores cimarronadas.

34 AGI, Santo Domingo, 81. Lope de Vega Portocarrero a S.M., 26 de abril de 1594.

35 AGI, Santo Domingo, 51. Lope de Vega Portocarrero a S.M., 28 de febrero de 1589.

36 AGI, Santo Domingo, 11. Juan Ochoa de la Vega, 10 de mayo de 1559.

37 Este término designa a mulatos muy oscuros.

38 AGI, Santo Domingo, 73. El Concejo a S.M., sin fecha. 
Esto ofrece una señal de lo temprano que se constituyeron palenques alrededor de lo que pronto se conocería sintomáticamente como El Maniel.

El palenque, aunque mecanismo más generalizado de rebelión, no llegó a adquirir exclusividad. Se registraron algunos conatos de rebeliones en zonas pobladas. La más importante de ellas fue la dirigida por el criollo Perico en el ingenio Casuí, a orillas del río de ese nombre. Esta obedeció al patrón de rebelión en una unidad tendente a desencadenar una insurrección general. A fines de $1585, \mathrm{Pe}$ rico urdió una conjura que tuvo éxito en generar el levantamiento de varias decenas de esclavos de ese ingenio, quienes dieron muerte a su propietario, Diego de Valdés, al capitán Martín Peguero y a numerosos otros blancos y mulatos. Los rebeldes se dedicaron a incendiar las haciendas cercanas y obtuvieron la adhesión de otros esclavos, al grado que la tropa abiertamente insurrecta alcanzó los setenta individuos. En medio de los hechos, Perico dispuso la conformación de un sistema jerárquico de autoridad. Cuando el caudillo se proponía atacar un hato de Diego Caballero Bazán, en Zavita, éste armó una pequeña formación con la que logró, según su propio testimonio, disolver la de los esclavos. ${ }^{39}$ No obstante, casi todos pudieron escapar, incluyendo a Perico. La Audiencia envió un contingente de las milicias para recoger los rebeldes desparramados. ${ }^{40}$

Con motivo del ataque del corsario Francis Drake a Santo Domingo, en 1586, a pesar de que los negros alzados no se movieron, las autoridades comprendieron que tenían un flanco débil que había que neutralizar. A tal efecto, se abrió una equívoca actitud de negociación; los negros reiteradamente se negaron a aceptar las ofertas, temiendo que fueran una trampa. Después de varios altos y bajos, finalmente una parte de los apalencados del Bahoruco, hacia 1602 aceptó asentarse en situación pacífica en el valle de San Juan, ${ }^{41}$ cuya villa, como se ha visto, había quedado disuelta; después del

39 AGI, Santo Domingo, 15. Información de servicios de Diego Caballero Bazán. Citada por Utrera, Historia Militar..., tomo II, págs. 85-86.

40 AGI, Santo Domingo, 51. Memorial de Cristóbal de Ovalle a S.M., 23 de febrero de 1586 .

41 Lugo, Historia..., pág. 191. 
temor a los ataques de los cimarrones se sumó el atractivo por zonas costeras para el ejercicio del contrabando. Esto se llevó a cabo por iniciativa del capitán Antonio de Ovalle, quien obtuvo el cargo de corregidor de los pacificados y de todos los negros y grifos de la zona. Esta situación no pasó de efímera: el torbellino que conllevaron las devastaciones de 1605 y 1606 trajo consigo que los pacificados se volvieran a alzar. A raíz de la segunda despoblación que abarcó el valle de San Juan únicamente, se contaron veintinueve negros y grifos del corregidor. Mientras tanto, se informaba de más de quinientos negros alzados en las zonas devastadas, unos dedicados a los rescates y otros "haziendo muchos daños, urtos y robos." 42

Esto formó parte de un estado generalizado de rebelión contra la medida real. Los movimientos contestatarios los comenzaron los mismos propietarios. Una parte de los vecinos de La Yaguana escaparon al oriente de Cuba, donde fueron perseguidos por la Real Audiencia. Los vecinos de Bayajá y otros puntos de la costa norte se congregaron en actitud rebelde en el valle de Guaba, donde por meses se resistieron a acatar las órdenes. ${ }^{43}$ El sistema de contrabando había involucrado a una porción importante de esclavos y otros libres de color, quienes, junto a los llamados tangomangos, ${ }^{44}$ se encargaban de realizar las transacciones arriesgadas, por lo general de contrabando. Eso explica que los esclavos se sumaran a las acciones de resistencia. En algunos casos formaron parte de los grupos rebeldes de blancos. Empero, fue mucho más generalizado el patrón de que se alzaran por su cuenta y constituyeran bandas irregulares dedicadas a sostener el negocio del contrabando. Muchos de ellos retornaron a las zonas occidentales después de haber sido deportados con sus amos a Monte Plata y Bayaguana. Fueron sometidos a

42 AGI, Santo Domingo, 83. De Baltasar de Monasterio a S.M., Sevilla, fecha confusa de 1606.

43 Detalles al respecto, en Incháustegui, Reales Cédulas..., tomo III, pág. 831 y ss.; Lugo, Historia..., pág. 147 y ss.

44 Los tangomangos, o Tangomäos como eran llamados, eran unos negros que se dedicaban a capturar esclavos alzados. Los fugitivos que eran capturados generalmente los cambiaban por productos alimenticios y ropas. Estos grupos tenían su zona de operación por la parte norte de la isla. Esta operación era realizada por los portugueses en las costas africanas. 
persecución tenaz, en general efectiva por cuanto carecían de experiencia bélica, en tanto que la Audiencia mantenía un contingente de tropas profesionales recién llegadas a la isla recorriendo las zonas devastadas. Según una información del momento, en los meses inmediatamente posteriores a las despoblaciones ciento veintidos negros insurrectos fueron capturados, de los cuales seis fueron ejecutados. ${ }^{45}$ Es probable que el núcleo mayor en la zona de La Yaguana tuviese por líder al esclavo Miguel Biáfara, ahorcado junto a seguidores.

Empero, los núcleos insurgentes que se formaron a raíz de las devastaciones distaron de ser aniquilados. Algunos se retiraron a zonas muy remotas, donde continuaron los rescates con navíos extranjeros. Uno de esos grupos está bien reseñado, pues fue asaltado por las tropas profesionales recién llegadas de Puerto Rico para aplastar la resistencia que se esperaba de la medida real. Operó durante más de dos años en la zona de Tiburón, el extremo occidental de la isla, y estaba compuesto mayoritariamente de esclavos fugitivos, aunque contaba con al menos un francés y un gallego. En la primera arremetida, fueron capturadas nueve negras y un negro, que fue ahorcado. Este informó que quedaban veintisiete negros y once negras, respecto a los cuales se dispuso que fuesen capturados. ${ }^{46}$ En la misma época, una expedición desde Cuba logró capturar más de veinte esclavos en la zona de la Mole de San Nicolás, extremo noroccidental de la isla. ${ }^{47}$

A pesar de las reiteradas batidas de las tropas del presidio sobre las costas occidentales, los grupos de alzados negros sobrevivieron varios años, a diferencia de los de blancos y mulatos de Guaba, que a los pocos meses se dispersaron. En la mencionada zona de Tiburón, tres años después de la información contenida en el pará-

45 AGI, Santo Domingo, 72. La información coincide con la relación que cita Lugo, que aunque incluye muchas menos personas, pues se restringe a La Yaguana, ofrece sus nombres. Todavía la generalidad de esos negros se apellidaban por sus etnias: biáfara, zape, bran, angola, mandinga. Dos esclavas eran mulatas. Unos pocos de los insurrectos eran negros libres. Lugo, Historia..., págs. 199-201.

46 Incháustegui, Reales Cédulas..., tomo III, pág. 864 y ss.

47 Ibídem, pág. 866. 
grafo anterior, seguía intacto un amplio grupo de cimarrones, de acuerdo a la información ofrecida a la Audiencia por Agustín Brito, dueño de una fragata, quien fuera hecho prisionero por piratas ingleses que rescataban con los cimarrones. ${ }^{48}$ Brito fue llevado a una "población dellos, que serían como cinquenta, muy ladinos, y allí asistió con ellos quatro años, y que por junio del año pasado, llegaron al puesto de la Sabana, tres nabíos, los dos yngleses y el otro Flamenco, con los quales los negros habían rescatado..."

El presidente tomó medidas enérgicas para la erradicación de "aquella ladronera a los piratas,(dando) órdenes precissas a mi hijo para que sino pudiesen ser habidos todos los negros que son en cantidad 73 dejase de presidio en aquellos puertos a el sarjento Flores con hasta 40 hombres y entre ellos algunos monteros y rastreros." La información ulterior de Gómez de Sandoval da cuenta de choques con los piratas pero no informa si, finalmente, fueron reducidos los cimarrones. De seguro, durante décadas sobrevivió una población de alzados, hasta el momento en que esos territorios occidentales fueron copados por piratas y bucaneros.

\section{Determinaciones del fin del cimarronaje y los últimos hechos}

La colonia quedó tan debilitada con las devastaciones que, después de la sujeción de los habitantes deportados, no se planteó la reducción de los cimarrones en las zonas donde su presencia era conocida. Estos subsistieron y en forma reiterada renovaron los ataques en las décadas siguientes. Como ha sido señalado, esto constituye una señal de la prolongación de tendencias socioeconómicas. Es inequívoco que la producción esclavista se prolongó hasta pasada la mitad de siglo. El abuso sistemático y cruel, como medio central de sujeción del esclavo, se mantuvo incólume. La persistencia de la esclavitud clásica, aunque su decadencia se acelerara, debe atribuirse, en primer término, a las disposiciones emanadas de la Corona destide 1611 .

48 AGI, Santo Domingo, 54. De Diego Gómez de Sandoval a S.M., 29 de mayo 
nadas a que la navegación comercial con la isla no se interrumpiera. ${ }^{49}$ En fin de cuentas, aunque en condiciones desventajosas, siguió exportándose cacao, tabaco, jengibre, azúcar y cueros. La navegación comercial se mantuvo activa hasta avanzada la década de 1640, como se comprueba en las tablas de movimiento desde Sevilla que elaborara Chaunu. ${ }^{50}$ En consecuencia, en la primera mitad del siglo XVII se mantuvo el esquema institucional y social proveniente del siglo anterior. El número de esclavos estaba en disminución, pero como fenómeno lento. Tras la invasión de Drake se produjo una epidemia que exterminó la mitad de los esclavos entonces existentes. Cierto que en los años ulteriores, la intensificación del contrabando conllevó la introducción de por lo menos seiscientos bozales en las zonas occidentales. A ello se agrega la reimplantación de la trata, con sus secuelas colectivas en materia de identidad. Pero, no parece que las cuantías de introducidos fueran muy elevadas. Después de los once mil esclavos registrados en 1606, esa cifra debió decrecer de manera continua. Sucesivas epidemias diezmaron la población esclava, principalmente en la década de $1660 .{ }^{51}$

La escasez de esclavos y la creciente dificultad de su introducción después de 1650 otorgaron un significado de extrema delicadeza al problema de los palenques. Adquiría una connotación económica, ya que los rebeldes profundizaban la carestía de mano de obra. En el entorno de decadencia que experimentaba la economía colonial, crecían los temores de que los cimarrones pudiesen hacerse con el control de la isla.

Pero, en lo inmediato, desde la década de 1640 comenzó a tener presencia el enemigo extranjero, mucho más peligroso que el esclavo insurrecto. Es ante la creciente amenaza que representara cuando se originó un cambio general de actitudes de los grupos dirigentes en sus relaciones con los libres de color y aun los esclavos. Se tuvieron que dar pasos firmes para la integración de los negros y mulatos en esquemas militares, particularmente en compañías

49 Así se ve en Incháustegui, Reales Cédulas..., tomo III, pág. 861 y ss.

50 Chaunu, Pierre: Seville et l'Atlantique, 8 vols., Paris, 1955-1959.

51 Cassá, Historia Social..., tomo I, pág. 108. 
de milicias de pardos y morenos. Esta incorporación, significaba, tácitamente, el reconocimiento de cierto espacio en la vida social. Mientras tanto, las manumisiones comenzaban a generalizarse debido al cese de rentabilidad de las unidades productivas y la conveniencia de sistemas de trabajo que acordaban independencia al esclavo, los cuales sólo tenían sentido cuando este último tenía el incentivo de la virtual manumisión.

Con motivo de la invasión de Penn y Venables, en 1655, las autoridades españolas hicieron saber formalmente a los apalencados de El Maniel que aceptarían su apoyo a cambio de garantizarles la libertad. Los negros no aceptaron, aunque en este caso tampoco se dispusieron a apoyar a los ingleses. Esta renuencia a la integración evidencia un desfase creciente entre la acción de los agentes y los condicionamientos estructurales crecientes. Es decir, en el contexto de desarticulación de la esclavitud de plantación, los alzados preferían mantenerse en libertad; y, por lo que señala la citada carta del arzobispo de 1662, tal actitud gozaba de la aquiescencia de la mayoría. Ahora bien, paralelamente, se comenzó a evidenciar el espacio integrativo a los negros libres. Estos operaron con un interés propio, no sólo distinto, sino incluso contrapuesto al de los esclavos, como se hizo generalizado en el siglo XVIII. ${ }^{52}$

Ahora bien, como la manumisión comenzaba a formar parte de la lógica del sistema económico, estaría llamada a crear expectativas cruciales entre los esclavos. La persistente rivalidad con la colonia vecina determinó una estrategia de manipulación de los esclavos: en la parte española, con fines integrativos y defensivos, y en la parte francesa, subversivos. La señal más clara de lo último estuvo representada por la recepción de los esclavos escapados en los años 80, a partir de quienes se fundaría la aldea de San Lorenzo de los Minas. Se atenuaría así la oposición entre libres y esclavos e, incluso, entre estos últimos no se plantearía un proyecto social segmentado. De ahí que, después de 1667, los documentos sean mudos acerca de cimarrones, en tanto que algunos explícitamente los refieren como cosa pasada. En el siglo XVIII no se cons-

52 Información de Raimundo González. 
tituyeron palenques, a no ser los de las zonas fronterizas compuestos por fugitivos de Saint Domingue. Explícitamente, muchos de ellos no se acogían a los ofrecimientos de los españoles, no sólo por generar un instinto refractario respecto a todos los blancos, sino porque se produjeron devoluciones por presión de las autoridades de la colonia vecina. Aun así, se practicaron reducciones de estos cimarrones, siendo la más importante una establecida en el valle de Neyba. En los palenques fronterizos de la segunda mitad del XVIII, la presencia de fugitivos de la parte española parece haber sido minúscula.

Mientras el giro en cuestión no cobró cuerpo, a las autoridades se les hizo inevitable recurrir a la reducción violenta. Las tentativas se sucedieron entre 1650 y 1667, fecha esta última en que culminaron con éxito. Cada vez más, las milicias disponían de medios aptos para enfrentar los cimarrones, ya que estaban engrosadas con muchos libres de color, una parte de ellos altamente experimentados como lanceros y monteros de hatos y hatillos. Los palenques de El Maniel tuvieron que tomar fuertes precauciones contra la posibilidad de traiciones o de localización por monteros experimentados. De todas maneras, como seguían contando con el apoyo de la masa esclava, se dificultaba su reducción. Pero, precisamente, se iba minando el fundamento de esta base de sustento.

El primer ataque de las milicias que hemos localizado, de 1650, lo encabezó Damián del Castillo, personaje que no por casualidad alcanzó protagonismo en la derrota de la expedición inglesa, cinco años después. Esta campaña se llevó a cabo tomando en consideración el peligro que representaban los alzados en caso de una invasión de ingleses o franceses. Cuando las milicias de la capital y La Vega pernoctaban una noche fueron atacadas por los insurgentes, quienes les provocaron varios heridos y un muerto. Inmediatamente los perseguidos se diseminaron en varios grupos, pero eso no impidió que tras días de rastreos uno de los grupos de milicia localizara un palenque, capturando sólo dieciocho esclavos. La gran mayoría pudo escapar, y no se les persiguió porque las provisiones de los milicianos se estaban agotando. De todas maneras, en la refriega fue muerto uno de los capitanes llamado Juan Angola, quien, de acuer- 
do a la relación oficial del suceso, "peleó valerosamente". ${ }^{53}$ Otro de los capitanes, reincidente en su actitud, fue condenado "a muerte de horca y hacer quartos y poner su cabeza en una escarpia." Un tercero murió en la cárcel, salvándose de ser ejecutado. Los demás fueron deportados perpetuamente de la isla y sometidos a doscientos azotes.

Como los restantes alzados habían quedado intactos, en represalia, bajaron a la zona de Nigua a atacar ingenios. Se interpretó que procuraban comida, pues las milicias les habrían destruido sus conucos. Del ingenio de Baltasar de Figueroa robaron además algunos esclavos. Esto motivó una nueva campaña de las milicias, las cuales penetraron a la sierra por dos puntos: los procedentes de La Vega, en número de cincuenta, al mando de Juan Sánchez Aragonés, partieron de Bonao hacia El Maniel Nuevo y Yuma; las milicias de Azua, comandadas por el capitán Pedro Ramírez, con sesenta hombres, "todos a propósito para penetrar las montañas", se internaron por El Maniel Viejo, la actual Ocoa. Estas tropas no localizaron cimarrones. En esos días, una partida de veinte de éstos volvió a atacar el llano, siendo seguida por un destacamento de milicias que no perdió el rastro hasta dar con los bohíos, que procedieron a incendiar, donde capturaron nueve negros más, entre quienes se hallaron dos robadas en el ingenio de Figueroa.

En definitiva, el grueso de insurrectos se mantenía en alzamiento, situación que no variaría durante muchos años. Quizás les ayudó una reubicación en lugares nuevos, más cercanos al remoto y frío macizo que hoy se conoce como Valle Nuevo; otros se habrían dirigido al sur del macizo central, cuya cumbre más elevada es $\mathrm{Pi}$ co Duarte. A las autoridades llegó la versión de que se produjo una escisión entre los rebeldes, por divergencias tácticas que involucraban porciones étnicas:

"Y haviendo tenido noticias que los criollos del Maniel abían apartado de sí a los Angolas a causa de decir que por ellos los yban a perseguir a su tierra los blancos, y que se abian retirado más de cin-

53 AGI, Santo Domingo, 57. Juan Melgarejo Ponce de Leon a Su Majestad, 18 de marzo de 1650. 
quenta leguas la sierra dentro a las faldas del Oeste que mira hacia el Valle de San Juan..." 54

A inicios de la década de 1660 se levantaron diversos expedientes tendentes a acabar de una vez con los núcleos de cimarrones de El Maniel. Aparentemente, éstos se habían reconstituido con facilidad tras lo sucedido en 1650, retornando al poco tiempo a las zonas de más familiares de habitat. No obstante, como lo muestran las informaciones registradas con motivo de las operaciones llevadas a cabo, en realidad ni siquiera se pudo averiguar de la existencia de varios palenques, que siguieron desenvolviéndose con normalidad.

La determinación de erradicar el cimarronaje quedó facilitada por la invasión inglesa de 1655. Mientras tanto, además del incremento de la pericia de los milicianos, prácticamente toda la población masculina adulta, con excepción de los cada vez más escasos esclavos, se había enrolado a las milicias. Sobrevino un estado de militarización, como nota distintiva de la vida social y recurso último de subsistencia de la comunidad.

Por medio de la real cédula del 30 de agosto de 1664 se ordenó que se agotaran todos los recursos para liquidar la cuestión cimarrona. Como parte de la nueva estrategia de solidaridad de todos los sectores para enfrentar las amenazas externas, se acudió a garantizar la libertad a los alzados, ofreciéndoles su reducción en pueblos, con prerrogativas semejantes a las de cualesquiera otros súbditos de la corona. A tal efecto, se envió a un ladino familiar de uno de los líderes de los cimarrones. De nuevo, éstos no mostraron ningún interés, "porque los demas de los presidentes an tratado de ir con jente a tratar de cojer estos negros y algunos an ydo con el hecho y aver sido muy poco el fruto que desto se a sacado, porque siempre tienen tiempo de huirse y an sido muy pocos los que se an coxido y mucho el gasto..." 55 Sabiendo por adelantado que tales gestiones no podrían prosperar, el presidente de la Audiencia se dilataba en emprender los pasos para la pacificación.

54 Ibídem.

55 AGI, Santo Domingo, 61. Pedro Carvajal y Cobos a S.M., Santo Domingo, 6 de marzo de 1666. 
Cuando se resolvieron detalles del sistema de defensa de la ciudad, se pasó finalmente a conceder atención al cimarronaje. El presidente envió a prácticos a recorrer las montañas, lográndose, en febrero de 1665, la ubicación de una aldea de alzados conocida como Siete Cabezas. Para eludir la red de espionaje de los negros, se hizo correr el rumor de que se aproximaba una nueva expedición inglesa, bajo cuyo pretexto se hicieron los despliegues para acometer por sorpresa a Siete Cabezas. Salvo los cabos del presidio, nadie fue informado del destino que tendrían. De manera que los espías que se despacharon desde Siete Cabezas con motivo de los movimientos de tropas no tuvieron tiempo de dar aviso de lo que se hallaba en juego. En la embestida al palenque se capturaron cuarenta de sus habitantes, en tanto otros escaparon o murieron en la refriega. Posteriormente se montaron emboscadas, dando por resultado nuevas muertes y la captura de veinte individuos más. En juicio, fueron condenados a muerte el fundador del poblado, veintisiete años antes, y otro calificado como su gobernador; a los demás se les sometió a azotes y se devolvió a sus dueños, previo pago de la mitad de su valor para repartirlo como botín a los milicianos que participaron en la expedición, tocando a cada uno cerca de ocho pesos.

Se dispuso una segunda expedición, que, como era característico, no arrojó ningún resultado, ya que los rebeldes supervivientes habían abandonado las aldeas dispersándose en pequeños grupos en zonas remotas. El presidente decidió esperar que se reagruparan y retornaran a una situación de normalidad que tornara exitosa una campaña de exterminio.

La reiteración del comportamiento, efectivamente, confirió eficacia a una operación de total erradicación de los cimarrones de El Maniel desde finales de 1666, la cual se prolongó durante más de cinco meses. Parece que la tropa que comenzó la campaña estuvo comandada por el capitán Juan Muñoz Cordero, la cual ocupó el palenque principal, ubicado en un emplazamiento muy abrupto. ${ }^{56}$ De inmediato, se dio aviso para que avanzaran los contingentes de

56 AGI, Santo Domingo, 62. Información a S.M. del presidente de Santo Domingo, Pedro de Carvajal y Cobos, sobre servicios de Juan Muñoz Cordero, 28 de julio de 1667. 
tropas del presidio y de las milicias distribuidas en puntos diversos de acceso a la cordillera, y que en total superaban trescientos individuos; posteriormente, esta tropa fue reforzada con numerosos efectivos. Esta concentración se hizo en vista del diseño de un operativo de cerco combinado con limpiezas sistemáticas de todos los parajes en que se pudieran ocultar los fugitivos. Al principio, estuvo al frente el presidente de la Audiencia, Pedro de Carvajal y Cobos, y, al enfermarse, pasó el mando a Lucas de Berroa, sargento mayor de la fortaleza, quien todo el tiempo se mantuvo en un puesto de mando central en llanura. ${ }^{57}$

Parece que el cerco alcanzó pleno éxito a causa de la p̀resentación de un cimarrón, que a cambio de su libertad y la de algunos españoles, se prestó de guía contra sus antiguos compañeros. El presidente pudo proclamar, con probable razón, que todos los alzados, en número todavía de alrededor de cuatrocientos, quedaron sometidos a la fe católica y a la obediencia al rey. ${ }^{58}$ Unos ciento cuarenta fueron capturados, ciento treinta "reducidos con agasajo", en tanto que los restantes perecieron en la prolongada campaña. Esto último, evidencia que la resistencia no dejó de ser muy tenaz.

Empero, los castigos administrados fueron mínimos y en extremo moderados. Por otra parte, muchos de los capturados no fueron devueltos a los antiguos amos ni deportados de la isla. Se engrosaron, así, las compañías de pardos y morenos. Se precipitaban los imperativos de la política defensiva a medida que los bucaneros ganaban terreno, los piratas apretaban el cerco y la economía caía en bancarrota absoluta en el funesto año de los "tres seis", recordado por la combinación de epidemia, terremoto y ciclón.

57 AGI, Santo Domingo, 89. Alvaro Girón y otros a S.M., I de agosto de 1667.

58 AGI, Santo Domingo, 2. Pedro Carvajal y Cobos a S.M. 28 de julio de 1667. 